\title{
Malmquist yöntemi: Karadeniz Bölgesi’nin turizm verimliliği üzerine bir uygulama
}

\section{Malmquist method: An application on the tourism efficiency of the Black Sea Region}

\author{
Murat GÜL*1,a, Timur ARSLAN²,b \\ ${ }^{I}$ Giresun Üniversitesi, Fen Edebiyat Fakültesi, İstatistik Bölümü, 28200, Giresun \\ ${ }^{2}$ Giresun Üniversitesi, Fen Edebiyat Fakültesi, İstatistik Bölümü, 28200, Giresun
}

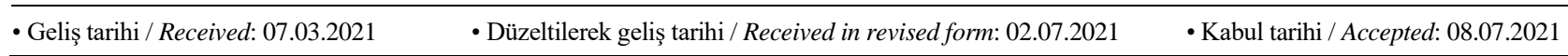

Öz

Malmquist yöntemi klasik Veri Zarflama Analizindeki statik incelemedeki eksikliği gidermek amacıyla geliştirilmiş parametrik olmayan bir yöntemdir. Verimliliği konu alan tüm araştırmalar genellikle klasik Veri Zarflama Analizi ile yapılmaya çalışııış. Bu yüzden dinamik bir Veri Zarflama Analizi olan Malmquist yöntemini kullanan çalışmalar sınırlı kalmıştır. Bu çalışmanın amacı verimliliğin zaman içerisinde nasıl değiştiğine izin veren Malmquist Toplam Faktör Verimlilik endeksini kullanarak Karadeniz Bölgesi'nde yer alan illerin turizm verimliliğini araştırmaktır. Bu çalışmaya göre illerin ortalama Malmquist Toplam Faktör Verimliliğinin \% 9.6 oranında arttığı ve bu artışta tamamen teknolojik değişim değerlerindeki ilerleme kaynaklı olduğu görülmüştür.

Anahtar kelimeler: Karadeniz Bölgesi, Malmquist toplam faktör verimliliği, Teknik etkinlik, Teknolojik değişim, Turizm verimliliği

\begin{abstract}
The Malmquist method is a non-parametric method developed to address the lack of static examination in classical data enveloping analysis. All research on efficiency was usually conducted with classical data enveloping analysis. That is why studies using the Malmquist method, a dynamic Data Enveloping Analysis, have been limited. Therefore, the aim of this study is to investigate this issue with the Malmquist Total Factor Efficiency index, which allows how the Tourism Efficiency of the provinces in the Black Sea Region changes over time. According to this study, the average Malmquist Total Factor Efficiency of the provinces has increased by $9.6 \%$, and this increase is entirely due to progress in technology change values.
\end{abstract}

Keywords: Black Sea Region, Malmquist total factor efficiency, Technical efficiency, Technological change, Tourism service

\footnotetext{
*a Murat GÜL; murat.gul@giresun.edu.tr, Tel: (0454) 31014 00, orcid.org/0000-0001-9950-699X

b orcid.org/0000-0003-1401-2697
} 


\section{Giriş}

Verimlilik; kaynak (girdi) ve ürün (çıktı) arasındaki oransal ilişki olup matematiksel olarak çıktının, girdiye bölümüdür (Kök ve Deliklitaş, 2003). Günümüzde ön plana çıkan rekabet olgusu neticesinde bir çıktıyı daha az girdiyle veya tek bir girdi ile daha fazla çıktı elde edebilme çabası verimlilik kavramının temelini oluşturmaktadır. Verimliliğin ölçülmesinde temel olarak parametrik ve parametrik olmayan yöntemler kullanılır. Regresyon analizi, faktör analizi ve stokastik sınır yaklaşımı (SFA) gibi parametrik yöntemlerde, üretim fonksiyonu önceden ayarlanır ve sonra hata terimi tahmin edilir. Geri hata yayılımı (BP) sinir ağı, yapay sinir ağı (YSA), hiyerarşik analiz, gri sistem teorisi (GST) ve Veri Zarflama Analizi (DEA) gibi parametrik olmayan yöntemlerde ise üretim fonksiyonunu önceden ayarlamaya ihtiyaç yoktur ve esas olarak doğrusal programlama yaklaşımı ile çözülür (Yi ve Liang, 2015).

Ancak Veri Zarflama Analizi modelleri verimliliğin uzun dönem veya zaman boyutunu yansıtmaz (Jingrong vd., 2015). Bu engeli aşmak için verimliliğin zaman içinde değişimini gösteren Malmquist endeksi kullanılmıştır (Caves vd., 1982a; Färe vd., 1994).

Turizm sektörü ise hâlihazırda dünya ekonomisinin hızla gelişen ve önemli bölümünü oluşturan sektörlerin başında gelmektedir. Bu anlamda 2018 y1lı verilerine göre Dünya Turizminde Türkiye gelen turist sayisinda 6. sirada, Turizm geliri bakımından 14.siradadır (UNWTO, 2019). Turizmin milli gelire sağladığ 1 katkı yanında, elde edilen döviz gelirleri sayesinde ödemeler dengesi açığını kapanmasında önemli bir rol oynamaktadır. Dünya Turizm Örgütü'ne göre, uluslararası seyahat ve turizm 319 milyon doğrudan ve dolaylı iş sağliyor ve dünya ekonomisinin büyümesini geride bırakarak küresel ekonomiye 8.8 trilyon ABD dolarlık katkıda bulunuyor (UNWTO, 2019). İç turizm de dikkate alınırsa bu rakamlar önemli ölçüde artacaktır. Bu yüzden Turizmde verimlilik her zaman ilgi odağ 1 olmuştur. Ancak verimlilik artış ve azalışlarına ait dinamik değişimleri parametrik olmayan sayısal yöntemlerle araştırılması sınırlı olmuştur.

Turizm faaliyetlerinin önemi göz önüne alındığında, çeşitli birimlerin ne kadar verimli olduğunu araştırmak ilginçtir. Bu birimler, oteller, turizm acenteleri ve hava alanları gibi farklı sektörlerdeki şirketler olabilir. Turizm endüstrisinde verimlilik değerlendirmesi, literatürde büyük ilgi görmüştür (Assaf, 2010;
Chen, 2007; Köksal ve Aksu, 2007). DEA, birden çok girdi ve çıktıyı işleyebildiği ve fonksiyonel form hakkında bir varsayım gerektirmediği için çok popüler olduğundan, üretim teorisine dayanan sınır kavramı açısından verimliliği tahmin etmenin ana yöntemi olarak, DEA modelleri, Turizm alanında birçok çalışmada verimlilik ölçümleri için kullanılmıştır (Johns vd., 1997; Anderson vd., 2000; Reynolds ve Biel, 2007; Barros ve Dieke, 2007).

Malmquist yöntemi, verimlilik artışının derecesini ve zaman içindeki değişim eğilimlerini tahmin etmek için yararlı bir yaklaşımdır (Caves vd., 1982a). Malmquist verimlilik endeksi kullanılarak, verimlilik değişikliği teknolojik değişim endeksine ve teknik değişim endeksine ayrıştırılabilir (Färe vd., 1994). Daha spesifik olarak, DEA tabanl1 Malmquist verimlilik endeksi, sadece iki farklı zaman periyodu arasındaki verimliliği karşılaştırmakla kalmaz, aynı zamanda her bir karar verme biriminin (KVB-Decision Making Unit-DMU) çalışma koşullarını göz önünde bulundurarak farklı zaman periyotlarında DMU'ların göreceli performansıyla verimliliği ölçer (Jafari, 2014). Bununla birlikte, Malmquist yöntemi, Turizm alanında çoğunlukla otel ve seyahat acentesi verimliliği gibi mikro birimlerin verimlilik ölçümleri için benimsenmiştir (Assaf ve Barros, 2011; Lee vd., 2012; Barros, 2007; Luo vd., 2014). Son olarak, önceki çalışmalar esas olarak mikro düzeydeki işletmelere odaklanmış ve ulusal ve yerel düzeydeki destinasyonların analizinden yoksundur. Assaf ve Dwyer (2013), turizm endüstrisinin verimlilik ölçümünün kamu politikası ve düzenlemesi için faydalı olabileceğini belirtmişlerdir. $\mathrm{Bu}$ nedenle, bir ülkenin veya bölgenin ekonomik büyümesini sağlamak için turizm için her türlü kaynağı en iyi şekilde yönetmek ve kullanmak için verimlilik değerlendirilmelidir. Bölgesel anlamda yıllara göre turizm verimliliği çok az ilgi görmüştür. $\mathrm{Bu}$ çalışma ile yukarıda tespit edilen boşluğu gidermek amaçlanmıştır.

Turizm oldukça mevsimlik bir sektördür; bu nedenle, zaman içindeki verimlilik değişikliklerini değerlendirebilen metodolojilerin dikkate alınması gerekir (Tsai vd., 2011). Aynı zamanda turizm, daha fazla turist çekmek ve gelirleri artırmak için performanslarını artırmak zorunda kalan bölgeler, iller arasında rekabetçi bir faaliyet olma eğiliminde olmuştur (Enright ve Newton, 2004).

Malmquist yöntemi, toplam faktör verimlilik değişikliğinin bir ölçüsünü elde etmek için panel verileri kullanır. $\mathrm{Bu}$ çalışmada Karadeniz 
Bölgesindeki iller karar verme birimi olarak ele alındı. Sadece belli bir dönem değil 7 yıl boyunca etkinlik değerlemesi yapılmış olması açısından da literatüre katkı sağlayacağı düşünülmektedir.

Turizm konusunda birçok çalışma yapılmasına rağmen bölgesel anlamda turizm verimliliği konusunda çok fazla çalışmaya rastlanmamaktadır. Karadeniz bölgesi Türkiye'de Turizm açısından gelişmekte olan bir bölgedir. $\mathrm{Bu}$ anlamda bu çalışmanın amacı makro ve ulusal düzeyde Karadeniz bölgesinin turizm verimliliğini yıllara göre Malmquist verimlilik endeksi ile ölçmektir. $\mathrm{Bu}$ araştırmanın sonuçlarından faydalanarak illerin performansını karşılaştırmak ve turizm ile ilgilenen genel ve yerel yöneticilere bir fikir vermektir.

\section{Materyal ve metot}

Veri Zarflama Analiz modeli ilk olarak Farrel (1957) 'in çalışmasına dayanan Charnes vd., (1978) tarafindan yapılan çalışmada sunulmuştur (Cooper vd., 2004).

Veri Zarflama Analizi, homojen yapıdaki DMU olarak adlandırılan ekonomik birimlere ait çok sayıda girdi ve çıktının karşılaştırılmasında, karar birimi göreli performans ölçümünde kullanılan metottur (Kecek, 2010). DEA modellerinde herhangi bir fonksiyonel ilişki ve dağılım varsayımı yapmadığından parametrik olmayan doğrusal programlama tabanlı bir yöntemdir (Shang vd., 2008).

\subsection{Malmquist yöntemi}

Malmquist yöntemi, Malmquist Toplam Faktör Verimlilik endeksine dayalı olarak verimliliğin zaman boyutunu dikkate alarak etkinliği ölçmek ve bu etkinliğin nedenlerini araştırmak amaciyla geliştirilen bir yöntemdir (Keskin, 2006).

Toplam Faktör Verimliliği (TFV) işletmelerin kararlı yapıda büyüme çalışmalarının değerlendirilmesinde temel bir gösterge olarak kullanılır. Toplam Faktör Verimliliği işletmelerin birbirleri ile aralarında ortaya çıkan gelişme ve büyüme farklılıklarının sebeplerini açıklamaktadır. Malmquist Toplam Faktör Verimliliğinin diğer bir faydası gelişme kaynaklarını ayırarak, işletme tarafından büyümenin ilerlemesini sağlayan unsur olarak hangi üretim faktörünün daha etkin bir şekilde üretimde kullanıldığının belirlenmesi açısından oldukça önemli bir kavram olarak karşımıza çıkmaktadır. İşletmeler kaynaklarını doğru biçimde kullanmak istediklerinden, büyüme aşamasında işletmelerin yeni kaynakların aranmasını mecbur kılarken diğer yandan mevcut kaynakların en etkin şekilde kullanılması problemini ortaya çıkarır (Vergil ve Abasız, 2008).

Malmquist Endeksi, Veri Zarflama Analizi (DEA) kullanılarak iki fonksiyon şeklinde elde edilmektedir. Bu fonksiyonlardan birincisi teknik değişimi, ikincisi ise teknolojik etkinlikteki değişimi tanımlar. $\mathrm{Bu}$ yüzden bu endeks parametrik yöntemler ve doğrusal programlama yöntemleri doğrultusunda hesaplanır (Liu ve Wang, 2008).

$\mathrm{Bu}$ endeks, her bir veri noktasının ortak teknolojiye göre nispi uzaklık oranlarını hesaplayarak, iki veri noktası arasındaki toplam faktör verimliliğindeki değişmeyi ölçer ve Malmquist (1953) tarafindan geliştirilen uzaklık fonksiyonuna dayalı olarak ifade edilir. Uzaklık fonksiyonları hem çıktı eksenli hem de girdi eksenli uzaklık fonksiyonları olarak tanımlanabilir (Deliktaş, 2002). Çıktı odaklı yaklaşımda, belirli bir girdiyle en fazla üretilecek çıktı miktarı (çıktı maksimizasyonu); girdi odaklı yaklaşımda ise, belirli bir çıktıyı üretmede kullanılacak en az girdi miktarı (girdi minimizasyonu) dikkate alınır. Bu durumda dual olan iki optimizasyon probleminin çözümü aynı etkinlik sınırını vermekte ama bazen etkili olmayan (etkinsiz) birimlerde farklılıklar ortaya çıkmaktadır (Keskin, 2006).

İlk defa Caves vd., (1982b) tarafından geliştirilen Malmquist Toplam Faktör Verimliliği endeksi, iki dönem arasındaki verimlilik değişimini her bir girdi-çıktı bileşimlerinin ortak teknolojik sınıra olan uzaklığını hesaplayarak ölçmektedir. Malmquist endeksini oluşturmanın ilk adımı uzaklık fonksiyonunu tanımlamaktır. Çıktıya göre uzaklık fonksiyonu

$D_{t}(x, y)=\min \{\delta:(x, y) / \delta \in P(x)\}$

olarak tanımlanmaktadır. Burada $x$ ve $y$, sirasıyla girdi ve çıktı değişkenlerinin matrislerini gösterir. $\delta$, çıktı yönlü bir verimliliği göstersin. $P(x)$ olası bir üretim sınırı olarak tanımlanır. $y$ vektörü, $P(x)$ sınırı (üretim sınırı) üzerinde ise, fonksiyonun değeri l'e eşit olacaktır. $y$ vektörü, $P(x)$ içindeki teknik olmayan bir noktayı tanımlıyorsa, fonksiyon değeri 1 'den büyük olacaktır. Tersine $y, P(x)$ dışında mümkün olmayan bir noktayı tanımlıyorsa, fonksiyon değeri 1'den küçük olacaktır (Deliktaş, 2002).

Eğer $\mathrm{t}$ dönemi teknolojisi referans teknoloji olarak alınırsa, iki dönem arasındaki toplam faktör verimliliğindeki değişme; 
$M_{t}=\frac{D_{t}\left(x_{t+1}, y_{t+1}\right)}{D_{t}\left(x_{t}, y_{t}\right)}$

Alternatif olarak eğer $\mathrm{t}+1$ dönemindeki teknoloji referans alınırsa;

$M_{t+1}=\frac{D_{t+1}\left(x_{t+1}, y_{t+1}\right)}{D_{t+1}\left(x_{t}, y_{t}\right)}$

Yukarıda gösterilen verimlilik endeksleri sadece teknoloji Hicks nötr ise eşit olacaktır. Bu yüzden hem kısitlayıcı bir varsayımdan kurtulmak hem de hangi dönemin referans alınacağı belirlemenin zorluğundan kurtulmak için Malmquist Toplam Faktör Verimliliği endeksi, iki endeksin geometrik ortalaması alınarak tanımlanmıştır.

$M_{t, t+1}=\left[\frac{D_{t}\left(x_{t+1}, y_{t+1}\right)}{D_{t}\left(x_{t}, y_{t}\right)} \cdot \frac{D_{t+1}\left(x_{t+1}, y_{t+1}\right)}{D_{t+1}\left(x_{t}, y_{t}\right)}\right]^{1 / 2}$

$M_{t, t+1}=$

$\frac{D_{t+1}\left(x_{t+1}, y_{t+1}\right)}{D_{t}\left(x_{t}, y_{t}\right)} \cdot\left[\frac{D_{t}\left(x_{t+1}, y_{t+1}\right)}{D_{t+1}\left(x_{t+1}, y_{t+1}\right)} \cdot \frac{D_{t}\left(x_{t}, y_{t}\right)}{D_{t+1}\left(x_{t}, y_{t}\right)}\right]^{1 / 2}$

Parantezin dışında yer alan terim, iki dönem arasındaki teknik etkinlikteki değişmeyi ölçmektedir. $\mathrm{Bu}$ oran spesifik girdi-çıkt1 bileşiminin iki dönem arasında en iyi üretim sınırına ne kadar yaklaşabildiğini göstermektedir. Parantez içindeki terim ise iki dönem arasındaki teknolojide meydana gelen değişmeyi açıklamaktadır. Üretim sınırları eğrisinin iki dönem arasında yer değiştirmesi ya da kayması olarak yorumlanmaktadır.

Malmquist Toplam Faktör Verimliliği endeksinin teknik etkinlikteki değişmeye ve teknolojik değişmeye ayrıştırılması her iki faktörün toplam faktör verimliliğine olan katkısını belirlemeye yarar. Böylece, denklem (5) iki bölüme ayrıldığında teknik etkinlikteki değişme ve teknolojik değişme ayrı ayrı ölçülebilir:

Teknik Etkinlikteki Değişim $(T E D)=$

$$
\frac{D_{t+1}\left(x_{t+1}, y_{t+1}\right)}{D_{t}\left(x_{t}, y_{t}\right)}
$$

Teknolojik Değişim $(\mathrm{TD})=$

$$
\left[\frac{D_{t}\left(x_{t+1}, y_{t+1}\right)}{D_{t+1}\left(x_{t+1}, y_{t+1}\right)} \cdot \frac{D_{t}\left(x_{t}, y_{t}\right)}{D_{t+1}\left(x_{t}, y_{t}\right)}\right]^{1 / 2}
$$

Teknolojik değişim karar birimlerinin üretim sınırı eğrisinde gerçekleştirdikleri kaymaları (frontier effect) gösterirken, Teknik etkinlikteki değişim ise karar birimlerinin üretim sınırını yakalama etkisini (catching-up effect) göstermektedir (Mahadevan, 2002).

Diğer yandan, TED ile TD çarpımı toplam faktör verimliliğindeki değişmeyi verir. Yani,

$M_{t, t+1}=\mathrm{TED} * \mathrm{TD}$

$M_{t, t+1}$ endeksinin 1'den büyük olması, toplam faktör verimliliğinin ( $\mathrm{t})$ döneminden $(\mathrm{t}+1)$ dönemine arttığını, bu değerin 1'den küçük olmas1, toplam faktör verimliliğinin ( $\mathrm{t}$ ) döneminden $(\mathrm{t}+1)$ dönemine azaldığını göstermektedir (Coelli, 1996).

\section{Bulgular}

Karadeniz Bölgesinde yer alan illerin Turizm Verimliliğinin zaman içerisinde nasıl değiştiğini Malmquist Toplam Faktör Verimlilik endeksi (MTFV) ile araştırmak için uygulama kısmında 2011-2018 y1lları arasında girdi ve çıktı değişkenleri Tablo 1'de gösterilmiştir.

Tablo 1. Turizm verimliliği için malmquist yönteminde kullanılan değişkenlerin tanımı

\begin{tabular}{ccc}
\hline Değişken türü & Tanım & Kaynak \\
\hline Girdi & Turizm işletme belgeli konaklama tesislerinde Tesise geliş sayısı (Yabanc1) & Türkiye İstatistik Kurumu* \\
Girdi & Turizm işletme belgeli konaklama tesislerinde Tesise geliş sayısı (Vatandaş) & Türkiye İstatistik Kurumu* \\
Girdi & Turizm işletme belgeli konaklama tesislerinde geceleme sayısı (Yabanc1) & Türkiye İstatistik Kurumu* \\
Girdi & Turizm işletme belgeli konaklama tesislerinde geceleme sayısı (Vatandaş) & Türkiye İstatistik Kurumu* \\
& İktisadi faaliyet kollarına göre cari fiyatlarla Gayrisafi Yurtiçi Hasıla (2009 bazlı & Türkiye İstatistik Kurumu** \\
Çıktı & Hizmetler) &
\end{tabular}

\footnotetext{
*Türkiye İstatistik Kurumu, 2019.
}

** Türkiye İstatistik Kurumu, 2020. 
Gelişmekte olan tüm ülkelerde yeterli sanayileşme olmadığ için hizmetler sektörünün GSYİH' aldığ1 pay yüksektir. Bu nedenle Türkiye'nin 2018 yılına göre hizmetler sektörü GSYİH'sının \%54'ünü oluşturmaktadır (Türkiye İstatistik Kurumu, 2021). Bununla beraber Türkiye'de hizmet sektörünün öncü alt sektörlerinden olan turizm sektörü, istihdamın yanında sağladığı döviz geliri ile ödemeler dengesi ve dış ticaret açı̆̆ının kapanmasında da çok önemli rol oynamaktadır (Özsağır ve Akın, 2012). Turizm gelirleri birçok çalışmada (Bayrak, 2018; Atan ve Arslantürk, 2015) çıktı olarak alınmıştır. Ancak Türkiye'de illere göre turizm gelirlerine ait veri bulunmadığından ve turizmin GSYİH'ya olan katkıs1 nedeniyle, GSYİH-Hizmetler çıtı değişkeni olarak alınmıştır.

Türkiye'de konaklama işletmeleri hukuki bakımdan bakanlık belgeli ve belediye belgeli olmak üzere ikiye ayrılmaktadır. Bakanlık belgeli olanlar Kültür ve Turizm Bakanlığı'nın, belediye belgeli olanlar ise bulundukları bölgedeki yerel yönetimlerin denetimi altında faaliyetlerini yerine getirir. Kültür ve Turizm Bakanlığg'nın 2018 yılı verilerine göre turizm işletme belgeli tesislerin toplam oda kapasitesi 464.927'dır. Belediye belgeli tesislerin toplam oda kapasitesi 231.001'dir. (Kültür ve Turizm Bakanlığı, 2019). Dolayisıyla toplam konaklama tesislerinin oda kapasitesi bakımından büyük bir kısmını oluşturan turizm işletme belgeli tesislerdir. $\mathrm{Bu}$ yüzden çalışmada girdi değişkeninde turizm işletme belgeli tesisler dikkate alınmıştır.

Bunun yanında tesise geliş sayısı birçok çalışmada (Cuccia vd., 2016; Kosmaczewska, 2014) girdi değişkeni olarak kullanılmıştır. Tesise geliş; Turizm İşletme Belgeli konaklama tesislerine geceleme yapmak amacıyla yapılan giriş sayısıdır. Tesise giriş sayısı kişi bazlı bir değişken olmayıp, aynı turistin farklı zamanlarda yaptığı girişler ayrı girdiler olarak kaydedilmektedir (İstanbul İl Kültür ve Turizm Müdürlüğü, 2021). $\mathrm{Bu}$ yüzden girdi değişkeni olarak tesise geliş sayısı ve onunla yakından ilişkili olan geceleme sayısı dikkate alındi.

Çıktı odaklı yaklaşımda, belirli bir girdiyle en fazla üretilecek çıktı miktarı (çıktı maksimizasyonu) baz alınmaktadır (Keskin, 2012) Yani ilave girdi kullanmadan, performans artışıla çıktıların artırılabileceği düzeyi yansıtmaktadır (Erdoğan,
2011). DMU (bu çalışmada il)'lar tarafından kullanılan kaynaklar girdi olarak kabul edilirken, DMU'ların üretim süreci sonunda ulaştığı sonuçlar çıktı olarak değerlendirilmektedir (Hwang ve Chang, 2003). Girdi ve çıktı değişkenlerin seçiminde çalışmanın kapsamına uygun olması, incelenen literatüre dayanması ve sağlıklı verilere ulaşılabilme durumu gözetilmiştir.

Tablo 1'deki girdi ve çıktı değişkenler kullanılarak Turizm verimliliğinin illere ve yıllara göre nasıl değiştiği gösterilmiştir. Çalışmada çıktı odaklı yaklaşım dikkate alınmıştır. Malmquist endeksinin bileşenleri olan teknik etkinlik ve teknolojik etkinlik değişim değerleri de illere ve yıllara göre bulunmuştur.

İki uzaklık fonksiyonun oranı olan TED, $\mathrm{t}+1$ ile $\mathrm{t}$ yılları arasında gerçekleşen üretimin maksimum potansiyel üretimden uzaklığını ifade etmektedir.

Teknik etkinsizlik, ilgili karar biriminin hem optimum girdi miktarı kullanmamış hem de uygun kapasitede çıtı üretememiş olduğunu yani kapasite kullanımının yanlış olduğunu ifade etmektedir. Teknik etkinlikte artış varsa bu dönemlerde ilgili karar biriminin hem kaynaklarını etkin kullandıklarını hem de uygun ölçekte (kapasitede) üretim yaptıklarını söylemek yanlış olmaz. Teknik Etkinliğin 1 den büyük olması ilgili karar biriminin kaynaklarını etkin kullandığını ve uygun kapasitede üretim yaptığını gösterir.

MTFV'nin bileşenlerinden, TED ve TD değerlerinin 1'den büyük olması teknik ve teknolojideki gelişmeleri ifade ederken, 1'den küçük olması teknik etkinlik ve teknolojideki gerilemeyi gösterir. Bir diğer ifade ile; TD'nin 1 'den büyük olması kapasite sınırının yukarı kaymasın1, TED'in 1'den büyük olması ise illerin üretim sınırını yakalama etkisini gösterecektir.

Teknik etkinliğinin birden küçük olduğu iller kaynaklarını iyi yönetememiş ve kullanamamıştır veya uygun olmayan kapasitede (ölçekte) çalışmışlardır. Bu illerin turizm hizmeti yapmaları için kapasitelerine uygun turizm hizmeti yapmaları ve dolayısıyla teknik olarak etkin olmaları sağlanmalıdır. Teknik etkinliği birden küçük olan iller en iyi turizm hizmet üretimi sinırını belirlemede başarısız olmuşlardır.

Söz konusu illerin bu başarısızlıktan dolayı rekabet etme güçleri zayıflamış ve rekabet ortamından düşmüşlerdir. İncelenen dönemde bu illerin kaynak kullanımındaki başarısızlıkları dikkat çekmektedir. 
Teknik etkinlik seviyelerindeki bu düşüşler genel olarak turizm verimliliğindeki yapısal sorunların varlı̆̆ına işaret etmektedir. Bu yapısal sorunların çözümü için yapısal önlemler gerekmektedir.

Tablo 2. 2011-2018 yılları arasında illerin teknik etkinlik değişim değerleri (TED)

\begin{tabular}{ccccccccc}
\hline & $\mathbf{1 1 = > 1 2}$ & $\mathbf{1 2 =} \mathbf{1 3}$ & $\mathbf{1 3}=>\mathbf{1 4}$ & $\mathbf{1 4 = > 1 5}$ & $\mathbf{1 5}=>\mathbf{1 6}$ & $\mathbf{1 6}=>\mathbf{1 7}$ & $\mathbf{1 7 = > 1 8}$ & Ortalama \\
\hline Düzce & 1.02461 & 0,62789 & 1.07478 & 1.24103 & 0.92249 & 1.25603 & 0.88922 & 1.00515 \\
Bolu & 1.13994 & 0.92255 & 1.07120 & 1.15054 & 0.82946 & 1.11951 & 0.84636 & 1.01137 \\
Zonguldak & 1.03566 & 0.58243 & 1.10921 & 1.42711 & 0.82288 & 1.01785 & 1.01475 & 1.00141 \\
Karabük & 1.21979 & 1.00556 & 0.91897 & 1.14855 & 0.81188 & 1.24047 & 0.71183 & 1.00815 \\
Bartın & 0.88459 & 1.06005 & 1.16490 & 1.0000 & 0.83889 & 0.53225 & 0.91910 & 0.91425 \\
Kastamonu & 0.76054 & 1.04642 & 0.67240 & 1.58539 & 0.94681 & 1.24491 & 0.71257 & 0.99558 \\
Sinop & 0.95454 & 0.97861 & 0.94994 & 0.74847 & 1.02633 & 0.89435 & 0.93636 & 0.92694 \\
Samsun & 1.0000 & 1.0000 & 0.89503 & 1.04158 & 0.77071 & 0.84246 & 0.97204 & 0.93169 \\
Tokat & 0.94362 & 1.05974 & 0.82649 & 1.03599 & 1.16789 & 1.0000 & 1.0000 & 1.00482 \\
Corum & 1.10224 & 1.17364 & 0.87606 & 1.16798 & 1.15232 & 0.97056 & 1.03033 & 1.06759 \\
Amasya & 0.99251 & 1.05645 & 1.11153 & 1.09936 & 0.73104 & 0.72448 & 0.82040 & 0.93368 \\
Trabzon & 0.93420 & 1.22440 & 1.01762 & 0.47521 & 2.27808 & 0.77630 & 0.91507 & 1.08870 \\
Ordu & 0.77533 & 0.90193 & 1.09300 & 0.94028 & 1.11697 & 0.70441 & 1.00312 & 0.93358 \\
Giresun & 1.12858 & 1.10627 & 0.92736 & 0.98617 & 1.02402 & 0.66216 & 0.91862 & 0.96474 \\
Rize & 0.78341 & 0.90192 & 1.20001 & 0.88737 & 1.27148 & 1.15204 & 0.67828 & 0.98207 \\
Artvin & 0.94967 & 1.41115 & 0.91814 & 1.19439 & 0.78875 & 1.23169 & 0.81540 & 1.04417 \\
Gümüşhane & 1.0000 & 0.94682 & 0.86687 & 1.18524 & 0.85116 & 0.98578 & 0.95925 & 0.97073 \\
\hline Ortalama & 0.97819 & 1.00034 & 0.98197 & 1.07733 & 1.02066 & 0.96207 & 0.89075 & 0.98733 \\
Maksimum & 1.21979 & 1.41115 & 1.20001 & 1.58539 & 2.27808 & 1.25603 & 1.03033 & 1.42582 \\
Minimum & 0.76054 & 0.58243 & 0.67240 & 0.47521 & 0.73104 & 0.53225 & 0.67828 & 0.63316 \\
Standart & 0.12963 & 0.19601 & 0.13879 & 0.24932 & 0.3613 & 0.228256 & 0.110813 & 0.20202 \\
Sapma & & & & & & & &
\end{tabular}

Yukarıdaki ifadeler doğrultusunda, illerin TED değerleri Tablo 2'de gösterilmiştir.

2011-2012 döneminde üretim sınırını yakalayan iller: Düzce, Bolu, Zonguldak, Karabük, Çorum, Giresun

2012-2013 döneminde üretim sınırını yakalayan iller: Karabük, Bartın, Kastamonu, Tokat, Çorum, Amasya, Trabzon, Giresun, Artvin

2013-2014 döneminde üretim sınırını yakalayan iller: Düzce, Bolu, Zonguldak, Bartın, Amasya, Trabzon, Ordu, Rize

2014-2015 döneminde üretim sınırını yakalayan iller: Düzce, Bolu, Zonguldak, Karabük, Kastamonu, Tokat, Çorum, Amasya, Artvin, Samsun, Gümüşhane

2015-2016 döneminde üretim sınırını yakalayan iller: Tokat, Çorum, Trabzon, Ordu, Giresun, Rize, Sinop

2016-2017 döneminde üretim sinırını yakalayan iller: Düzce, Bolu, Zonguldak, Karabük, Kastamonu, Rize, Artvin

2017-2018 döneminde üretim sınırını yakalayan iller: Zonguldak, Çorum, Ordu; Buna göre, ortalama teknik etkinlikte en büyük artış 2014 2015 döneminde \%7.7337'lik artıştır. Bu uygulamada 7 dönemde ortalama TED de ilerleme 2012-2013, 2014-2015 ve 2015-2016 dönemlerinde olmuştur.

2012-2013 döneminde ortalama teknik etkinlikte $\% 0.0348$ 'lik küçük bir artış gerçekleşirken, en büyük artış (\% 41.11) Artvin ve en büyük düşüş (\% 42) Zonguldak ilinde gerçekleşmiştir.

2014-2015 döneminde ortalama teknik etkinlikte $\% 7.7337$ 'lik bir artış olmuşken, en büyük artış (\%58.53) Kastamonu ve en büyük düşüş (\%52.48) Trabzon ilinde gerçekleşmiştir.

2015-2016 döneminde ortalama teknik etkinlikte $\% 2.0661$ 'lik bir artış olmuşken, en büyük artış (\%127.80) Trabzon ve en büyük düşüş (\%26.89) Amasya ilinde gerçekleşmiştir.

2011-2012 y1lında TED değerinde en büyük artış1 yaşayan il (\%21.97) Karabük olurken, en büyük düşüşü yaşayan ise (\%23.94) Kastamonu olmuştur.

2012-2013 y1lında TED değerinde en büyük artış1 yaşayan il (\%41.11) Artvin olurken, en büyük düşüşü yaşayan ise $(\% 42)$ Zonguldak olmuştur. 
2013-2014 yılında TED değerinde en büyük artı̧ı1 yaşayan il (\%20.0) Rize olurken, en büyük düşüşü yaşayan ise (\%32.76) Kastamonu olmuştur.

2014-2015 yılında TED değerinde en büyük artış1 yaşayan il (\%58.53) Kastamonu olurken, en büyük düşüşü yaşayan ise $(\% 52.48)$ Trabzon olmuştur.

2015-2016 y1lında TED değerinde en büyük artış1 yaşayan il (\%127.80) Trabzon olurken, en büyük düşüşü yaşayan ise (\%26.89) Amasya olmuştur.
2016-2017 y1lında TED değerinde en büyük artış1 yaşayan il (\%25.60) Düzce olurken, en büyük düşüşü yaşayan ise $(\% 46.78)$ Bartın olmuştur.

2017-2018 yılında TED değerinde en büyük artış1 yaşayan il (\%3.03) Çorum olurken, en büyük düşüşü yaşayan ise (\%32.18) Rize olmuştur.

Tablo 3. 2011-2018 yılları arasında illerin teknolojik etkinlik değişim değerleri (TD)

\begin{tabular}{ccccccccc}
\hline & $\mathbf{1 1 = > 1 2}$ & $\mathbf{1 2 = > 1 3}$ & $\mathbf{1 3 =}=\mathbf{1 4}$ & $\mathbf{1 4 = > 1 5}$ & $\mathbf{1 5}=\mathbf{1 6}$ & $\mathbf{1 6 = > 1 7}$ & $\mathbf{1 7 =} \mathbf{1 8}$ & Ortalama \\
\hline Düzce & 1.06178 & 1.12135 & 1.14659 & 0.83003 & 1.35413 & 1.16842 & 1.28517 & 1.13821 \\
Bolu & 0.92001 & 1.12813 & 1.25713 & 0.77072 & 1.35413 & 1.16842 & 1.28517 & 1.12624 \\
Zonguldak & 0.99306 & 1.07586 & 0.99785 & 0.93920 & 1.26574 & 1.11227 & 1.28374 & 1.09539 \\
Karabük & 1.08030 & 1.14452 & 0.97819 & 0.99017 & 1.16426 & 1.13621 & 1.26458 & 1.10832 \\
Bartın & 0.90231 & 1.30106 & 1.60054 & 1.87681 & 0.55943 & 1.05473 & 1.28966 & 1.22638 \\
Kastamonu & 0.86125 & 0.95255 & 1.66149 & 0.69128 & 1.29478 & 1.11882 & 1.19569 & 1.11084 \\
Sinop & 0.97000 & 1.05363 & 1.11224 & 0.99017 & 1.16426 & 1.11151 & 1.26871 & 1.09579 \\
Samsun & 1.05743 & 1.11574 & 0.97819 & 0.99017 & 1.16772 & 1.12307 & 1.27431 & 1.10095 \\
Tokat & 0.96957 & 1.39473 & 1.05004 & 1.20330 & 1.10779 & 0.80795 & 0.99628 & 1.07567 \\
Çorum & 0.97924 & 1.06656 & 1.17495 & 0.97527 & 1.27479 & 1.06646 & 1.26217 & 1.11421 \\
Amasya & 1.05987 & 1.12813 & 1.02195 & 0.92774 & 1.20314 & 1.11056 & 1.25592 & 1.10104 \\
Trabzon & 1.03722 & 1.14452 & 0.98354 & 0.92493 & 1.27726 & 1.13621 & 1.27274 & 1.11092 \\
Ordu & 1.01931 & 1.14467 & 1.03388 & 0.99017 & 1.16426 & 1.09342 & 1.27765 & 1.10334 \\
Giresun & 0.94602 & 1.08859 & 1.18041 & 0.90625 & 1.24260 & 1.07147 & 1.29321 & 1.10408 \\
Rize & 1.02771 & 1.11149 & 0.97819 & 0.99017 & 1.19863 & 1.12603 & 1.27282 & 1.10072 \\
Artvin & 1.08068 & 1.12462 & 1.19738 & 0.84830 & 1.35413 & 1.13707 & 1.26458 & 1.14382 \\
Gümüşhane & 0.93429 & 0.91000 & 1.45657 & 0.87399 & 1.27820 & 1.05721 & 1.20520 & 1.10221 \\
\hline Ortalama & 0.99412 & 1.11801 & 1.16524 & 0.98345 & 1.20149 & 1.09411 & 1.24986 & 1.11518 \\
Maksimum & 1.08068 & 1.39473 & 1.66149 & 1.87681 & 1.35413 & 1.16842 & 1.29321 & 1.40421 \\
Minimum & 0.86125 & 0.91000 & 0.97819 & 0.69128 & 0.55943 & 0.80795 & 0.99628 & 0.82920 \\
Standart Sapma & 0.06629 & 0.10971 & 0.21659 & 0.25563 & 0.18161 & 0.08134 & 0.07059 & 0.14025 \\
\hline & & & & & & & &
\end{tabular}

Teknolojik Değişim; yeni teknolojilerin benimsenmesinden, yeni hizmetlerden ve yeni yönetim sistemlerinden etkilenir.

Teknik etkinlik karar biriminin kapasitesinin etkin kullanım başarısını gösterirken, teknolojik etkinlik kapasite artırma başarısını ifade eder.

Teknik etkinlikteki değişim endeksinin birden büyük olması [(TED)>1], illerin en başarılı turizm kapasitesini yakalama durumunu (Chatching-up Effect) temsil ederken öte yandan Teknolojik değişim endeksinin birden büyük olması[(TD)>1] ise söz konusu en başarılı turizm kapasitesinin yukarı yönlü eğilim (trend)(Frontier-Shift Effect ) kazanması anlamına gelmektedir.

Tablo 3'te, illere ait ortalama TD değerleri gösterilmiştir. Teknoloji ya da verimliliği etkileyecek olan Turizm hizmet sürecine ait düzenlemeler, çevresel faktörler ve politikalardaki iyi gelişmeler 2012-2013 yılında \%11.80, 20132014 y1lında \%16.52, 2015-2016 y1lında \%20.14,
2016-2017 y1lında \%9.41 ve 2017-2018'de \%24.98 ortalama artış olarak kendini göstermiştir. İncelenen dönemler boyunca en büyük düşüş \%44.06 ile 2015-2016 döneminde Bartın ilinde yaşanmıştır. İncelenen dönemlerde, en yüksek teknolojik değişim \%66.14 ile Kastamonu ilinde ve 2013-2014 döneminde gözlenmiştir. 2011-2012 ve 2014-2015 dönemlerinde ise, iller turizm verimlilik sınırını yukarı hareketini gerçekleştirememiş ve kayıplar yaşamışlardır.

Teknolojik Değişimin 1'den büyük olduğu iller ilgili dönemde teknolojik gelişme göstererek aynı girdi miktarı ile daha fazla çıktı üretmeyi başarmışlardır. 7 dönemde TD değerleri bütün illerde sürekli değişimler yaşamıştır.

2015-2016, 2016-2017 ve 2017-2018 dönemlerinde 17 tane ilin 16'sında teknolojik değişim artış şeklinde olmuştur. Bu yüzden, illerin turizm verimlilik yeteneklerinde (yatırım, hizmet kalitesi, vb.) en çok gerilemenin olduğu ya da illerin teknolojik gelişmelere ulaşamadıkları 
dönemin ise 17 ilin yalnızca 2'sinde teknolojik değişiminde artış göstermesi sebebiyle 2014-2015 döneminin olduğu söylenebilir. Bir başka ifadeyle, ortalama olarak 2012-2013, 2013-2014, 20152016, 2016-2017 ve 2017-2018 dönemlerinde tüm illerin turizm verimlilik sınırı yukarı kaymış ve bu iller ilgili dönemlerde teknolojik gelişme sayesinde aynı girdi miktarıyla daha fazla çıtı üretmeyi sağlamışlardır. Tablo 2 ve Tablo 3 'teki değerler kullanılarak hesaplanan illere ait MTFV endeksleri, Tablo 4'te gösterilmiştir.

Tablo 4. 2011-2018 yılları arasında illerin turizm malmquist toplam faktör verimlilik endeksleri

\begin{tabular}{ccccccccc}
\hline & $\mathbf{1 1 = > 1 2}$ & $\mathbf{1 2 =}=\mathbf{1 3}$ & $\mathbf{1 3}=>\mathbf{1 4}$ & $\mathbf{1 4 =} \mathbf{1 5}$ & $\mathbf{1 5}=>\mathbf{1 6}$ & $\mathbf{1 6 = > 1 7}$ & $\mathbf{1 7 = > 1 8}$ & Ortalama \\
\hline Düzce & 1.08791 & 0.70409 & 1.23233 & 1.03010 & 1.24919 & 1.46757 & 1.14281 & 1.13057 \\
Bolu & 1.04876 & 1.04077 & 1.34665 & 0.88675 & 1.12321 & 1.30806 & 1.08772 & 1.12027 \\
Zonguldak & 1.02848 & 0.62662 & 1.10683 & 1.34034 & 1.04156 & 1.13213 & 1.30268 & 1.08266 \\
Karabük & 1.31775 & 1.15088 & 0.89893 & 1.13726 & 0.94525 & 1.40944 & 0.90017 & 1.10853 \\
Bartın & 0.79818 & 1.37919 & 1.86448 & 1.87681 & 0.46930 & 0.56138 & 1.18533 & 1.16210 \\
Kastamonu & 0.65502 & 0.99676 & 1.11719 & 1.09595 & 1.22591 & 1.39283 & 0.85203 & 1.04796 \\
Sinop & 0.92591 & 1.03110 & 1.05657 & 0.74111 & 1.19492 & 0.99408 & 1.18798 & 1.01881 \\
Samsun & 1.05743 & 1.11574 & 0.87551 & 1.03134 & 0.89998 & 0.94615 & 1.23869 & 1.02355 \\
Tokat & 0.91491 & 1.47806 & 0.86786 & 1.24661 & 1.29378 & 0.80795 & 0.99628 & 1.08649 \\
Corum & 1.07936 & 1.25177 & 1.02933 & 1.13910 & 1.46898 & 1.03506 & 1.30045 & 1.18629 \\
Amasya & 1.05195 & 1.19182 & 1.13593 & 1.01992 & 0.87955 & 0.80458 & 1.03037 & 1.01630 \\
Trabzon & 0.96897 & 1.40136 & 1.00088 & 0.43954 & 2.90970 & 0.88204 & 1.16465 & 1.25245 \\
Ordu & 0.79030 & 1.03241 & 1.13004 & 0.93103 & 1.30045 & 0.77022 & 1.28164 & 1.03373 \\
Giresun & 1.06767 & 1.20428 & 1.09468 & 0.89372 & 1.27246 & 0.70949 & 1.18797 & 1.06147 \\
Rize & 0.80512 & 1.00248 & 1.17385 & 0.87864 & 1.52404 & 1.29723 & 0.86333 & 1.07781 \\
Artvin & 1.02630 & 1.58701 & 1.09937 & 1.01320 & 1.06808 & 1.40053 & 1.03115 & 1.17509 \\
Gümüşhane & 0.93429 & 0.86161 & 1.26266 & 1.03589 & 1.08796 & 1.04217 & 1.15610 & 1.05438 \\
\hline Ortalama & 0.97402 & 1.12094 & 1.13489 & 1.04337 & 1.23261 & 1.05652 & 1.11231 & 1.09638 \\
Maksimum & 1.31775 & 1.58701 & 1.86448 & 1.87681 & 2.90970 & 1.46757 & 1.30268 & 1.76086 \\
Minimum & 0.65502 & 0.62662 & 0.86786 & 0.43954 & 0.46930 & 0.56138 & 0.85203 & 0.63882 \\
Standart & 0.15363 & 0.25705 & 0.22885 & 0.29467 & 0.49762 & 0.28194 & 0.14593 & 0.26567 \\
Sapma & & & & & & &
\end{tabular}

2011-2012 döneminde Malmquist Toplam Faktör Verimliliği en fazla artan il \%31'lik artış ile Karabük'tür ve bu artışın nedeni teknik etkinlik $(\% 22)$ ve teknolojik gelişim (\%8) kaynaklı olduğu bulunmuştur. Bu dönemde Kastamonu \%34 oran ile Malmquist Toplam Faktör Verimliliği en fazla azalan il olmuştur. Bunun nedeni ilin turizm verimliliğinin teknik etkinlikte (\%24), teknolojide (\%14) geriye gitmesidir.

2012-2013 döneminde Malmquist Toplam Faktör Verimliliği en fazla artan il \%59'luk artış ile Artvin'dir bu artışın nedeni teknik etkinlik (\%41) ve teknolojik gelişim (\%12) kaynaklı olduğu bulunmuştur. Bu dönemde Zonguldak \%37.34 oran ile Malmquist Toplam Faktör Verimliliği en fazla azalan il olarak bulunmuştur.

2013-2014 döneminde Malmquist Toplam Faktör Verimliliği en fazla artan il \%86'lik artış ile Bartın'dır ve bu artışın nedeni teknik etkinlik (\% 16) ve teknolojik gelişim (\% 60) kaynaklı olduğu bulunmuştur. $\mathrm{Bu}$ dönemde Tokat $\% 13.22$ oran ile Malmquist Toplam Faktör Verimliliği en fazla azalan il olarak bulunmuştur.
2014-2015 döneminde Malmquist Toplam Faktör Verimliliği en fazla artan il \%87.68'lik artı̧̧ ile Bartın'dır. Bu dönemde Trabzon \%56.05 oran ile Malmquist Toplam Faktör Verimliliği en fazla azalan il olarak bulunmuştur. Bunun nedeni ilin turizm verimliliğinin teknik etkinlikte (\%52.48), teknolojide (\%8) geriye gitmesidir.

2015-2016 döneminde Malmquist Toplam Faktör Verimliliği en fazla artan il \%190'lık artış ile Trabzon'dur bu artışın nedeni teknik etkinlik $(\% 127.8)$ ve teknolojik gelişim (\%27.7) kaynaklıdır. Bu dönemde Bartın \%53.07 oran ile Malmquist Toplam Faktör Verimliliği en fazla azalan il olarak bulunmuştur.

2016-2017 döneminde Malmquist Toplam Faktör Verimliliği en fazla artan il \%46.75'lik artış ile Düzce'dir bu artışın nedeni teknik etkinlik (\%25.60) ve teknolojik gelişim (\%16.84) kaynaklıdır. Bu dönemde Bartın \%43.87 oran ile Malmquist Toplam Faktör Verimliliği en fazla azalan il olarak bulunmuştur.

2017-2018 döneminde Malmquist Toplam Faktör Verimliliği en fazla artan il \%30.26'lık artış ile 
Zonguldak'tır. Bu dönemde Kastamonu \%14.79 oran ile Malmquist Toplam Faktör Verimliliği en fazla azalan il olarak bulunmuştur.

MTFV deki artışlar diğer illere göre, o ilin turizm verimliliği bakımından rekabet gücünün arttığını gösterecektir. MTFV deki azalı̧̧lar ise turizm verimliliği bakımından rekabet gücünün azaldığını gösterecektir.

Genel olarak 7 yıllık dönemde illerin ortalama toplam faktör verimliliğinin \%9.6 oranında arttığ ve bu artışta tamamen \% 11.5'lik teknolojik değişim değerlerindeki ilerleme kaynaklı olduğu görülmektedir.

Yine Tablo-4'ten; illerin ortalama MTFV'de 2012-2013'te \%12.09'lik, 2013-2014 döneminde $\% 13.48$ 'lik, 2014-2015'te \%4.33'lük, 2015-2016'da \%23.26'lik, 2016-2017'de \%5.65'lik, 2017-2018'de $\% 11.23$ 'lük bir artış görülmüştür. Bunun yanı sıra 2011-2012 döneminde \%2.59'luk bir azalış görülmüştür.

\section{Tartışma ve sonuçlar}

Malmquist Toplam Faktör Verimlilik Endeksi'nin en önemli özelliği, tüm verimlilik ölçüsünü biri teknik verimlilikteki değişimi ölçen, diğeri de teknolojideki değişimi ölçen iki özel bileşene ayırmasıdır. Teknik verimliliğin ve teknolojik gelişmenin yüksek olması karar birimi ya da sektör açısından yüksek bir ekonomik verimliliği kısaca yüksek bir rekabet gücünü ifade eder. Üretimin veya hizmetin ne derece verimli yapıldığ verimliliğin zaman içinde ne şekilde değiştiği, verimlilikteki değişmelerin ne kadarının teknik etkinlikteki değişmeden ne kadarının teknolojik değişmeden kaynaklandığını bilmek turizm verimliliği ve turizm planlaması bakımından önemlidir.

$\mathrm{Bu}$ çalışmanın amacı Karadeniz Bölgesinde yer alan illerin Turizm Verimliliğinin zaman içerisinde nasıl değiştiğine izin veren Malmquist yöntemi ile bölgenin Turizm Verimliliğini araştırmaktır. Elde edilen bulgulardan yola çıkarak; Karadeniz bölgesinin turizm verimliliğinin ölçülmesine yönelik sonuçlar sunulmaya çalışılmıştır.

MTFV deki artışlar diğer illere göre, o ilin turizm verimliliği bakımından rekabet gücünün arttığını gösterecektir. MTFV deki azalışlar ise turizm verimliliği bakımından rekabet gücünün azaldığını gösterecektir. MTFV, TED ve TD'nin il bazında değişimleri önceki bölümde ayrıntılı olarak sunulmuştur.
Çalışmanın ana bulguları, genel olarak 7 yıllık dönemde illerin ortalama toplam faktör verimliliğinin $\% 9.6$ oranında arttığı ve bu artışta tamamen \% 11.5'lik teknolojik değişim değerlerindeki ilerleme kaynaklı olduğu görülmektedir. İllerin, 7 yıllık dönemde genel olarak ortalama toplam faktör verimliliğinin \%9.6'dan daha yüksek olan iller: Düzce, Bolu, Karabük, Bartın, Çorum, Trabzon, Artvin'dir. Bu sonuçtan Batı Karadeniz'deki illerin Turizm verimliliğinin diğer illere göre daha iyi olduğu söylenebilir. 7 yıllık süreçte ortalama toplam faktör verimliliği artmasına rağmen fazla artmayan ilk 3 il: Sinop (\%1.9), Samsun (\%2.4), Amasya (\%1.6)'dır. Bu iller toplam faktör verimliliğini artırmak için daha fazla çaba göstermelidir.

İlerin ortalama MTFV' de 2012-2013'te $\% 12,09$ 'lik, 2013-2014 döneminde ise \%13.48'lik, 2014-2015'te \%4.33'lük, 2015-2016'da \%23.26'lk, 2016-2017'de \%5.65'lik, 2017-2018'de \%11.23'lük bir artış görülmüştür. Bunun yanı sıra 2011-2012 döneminde $\% 2.59$ 'luk bir azalış görülmüştür. Ortalama verimliliğin en fazla arttığı dönem 20152016 (\%23) dönemidir.

Çalışmanın literatüre katkısı iki şekildedir. Birincisi Turizm Verimliliğinin, Malmquist Verimlilik endeksi ile ölçmek için bir model kurulmuş ve bu model ile Turizm verimliliği ölçülmüş ve yıllara göre, MTFV deki artışlar ve azalışlar, o ilin turizm verimliliği bakımından rekabet gücünü göstermiştir. İkincisi bu çalışma Karadeniz Bölgesini içerdiği için bölgesel anlamdaki yerel turizm çalışmalarına, projelerine ve planlamalarına önemli bir katkısı olacaktır. Ayrıca bu bilgilerin ve sonuçların diğer turizm sektörü alanındaki çalışmalara da 1şık tutacağı düşünülüyor.

Malmquist yöntemi kullanılarak bölgesel turizm verimliliği bir diğer anlamda turizm rekabet gücü hesaplandı. Bunun yanı sıra verimlilik farkl11ıkları illerin (destinasyon) rekabetçiliği konusunda belirleyici bir husustur. Bölgenin sosyo-ekonomik kalkınmasına yönelik stratejik planlamada turizmin gelişmesine ve illerin Turizm verimliliğinin artırılmasına yönelik politikaların uygulanmasına ihtiyaç olduğu görülmektedir. Çalışmadan elde edilen sonuçlar, yerel yönetimlerin ve karar vericilerin iyileştirmeler yapmasına izin veren ayrıntılı yönetim anlayışları sağlayabilir. $\mathrm{Bu}$ çalışmanın sonuçları verimlilik esaslı olması bakımından bu anlayışlara ve stratejilere yardımcı olabilir. 


\section{Kaynaklar}

Anderson, R.I., Fok, R. and Scott, J. (2000). Hotel industry efficiency: an adavanced linear programming examination. American Business Review, 18, 40-48.

Assaf, A. (2010). The cost efficiency of australian airports post privatization: a bayesian methodology. Tourism Management, 31(2), 267-273.

https://doi.org/10.1016/j.tourman.2009.03.005

Assaf, A.G. and Barros, C. (2011). Performance analysis of the gulf hotel industry: a malmquist index with bias correction. International Journal of Hospitality Management, 30, 819-826.

Assaf, A.G. and Dwyer, L. (2013). Benchmarking international tourism destinations. Tourism Economics, $19, \quad 1233-1247$. https://doi.org/10.5367/te.2013.0354

Atan, M. ve Arslantürk, Y. (2015). Dünya ülkelerinin turizm etkinliğinin analizi. Gazi Üniversitesi İktisat ve İşletme Dergisi, 1 (1), 59-76.

Barros, C.P. and Dieke, P.U.C. (2007). Analyzing the total productivity change in travel agencies. Tourism Analysis, 12, 27-37. https://doi.org/10.3727/108354207780956708

Bayrak, R., (2018). OECD ülkeleri turizm sektöründe toplam faktör verimliliği. Çankırı Karatekin Üniversitesi İktisadi ve İdari Bilimler Fakültesi Dergisi, Cilt 8, Sayı 2, 157-177.

Caves, D.W., Christense, L.R. and Diewert, W.E. (1982a). Multilateral comparisons of output, input, and productivity using superlative index numbers. Economic Journal, 92, 73-86.

Caves, D.W., Christense, L.R. and Diewert, W.E. (1982b). The economic theory of index numbers and the measurement of input, output, and productivity. Econometrica, 50, 1393-1414.

Charnes, A., Cooper, W.W. and Rhodes, E. (1978). Measuring the efficiency of decision making units, European Journal of Operational Research, Volume 2, Issue 6, Pages 429-444.

Chen, C. F. (2007). Applying the stochastic frontier approach to measure hotel managerial efficiency in taiwan. Tourism Management, 28(3), 696702.

Coelli, T.J. (1996). A guide to deap version 2.1: a data envelopment analysis program. Center of Efficiency and Productive Analysis Working Paper. No:8.
Cooper, W.W., Seiford, M. and Zhu, J. (2004). Handbook on data envelopment analysis, Springer (Kluwer Academic Publishers), Boston.

Cuccia, T., Guccio, C. and Rizzo, I., (2016). The effects of UNESCO world heritage list inscription on tourism destinations performance in italian regions. Economic Modelling, 53, 494-508. https://doi.org/10.1016/j.econmod.2015.10.049

Deliktaş, E., (2002). Türkiye özel sektör imalat sanayinde etkinlik ve toplam faktör verimliliği analizi, ODTÜ Gelişme Dergisi, 29, ss.247-284.

Enright, M. J. and Newton, J. (2004). Tourism destination competitiveness: a quantitative approach. Tourism Management, 25(6), 777788.

Erdoğan, Ö. (2011). Banka etkinliklerinin risk odaklı yaklaşımla modellenmesi ve Türk bankacılık sektörü uygulaması. Yüksek Lisans Tezi, Kadir Has Üniversitesi Sosyal Bilimler Enstitüsü, İstanbul.

Färe, R., Grosskopf S., Lindgren B. and Roos, P. (1994). Productivity developments in swedish hospitals: A malmquist output index approach. in data envelopment analysis: Theory, Methodology, and Applications.pp. 253-272, Springer, Dordrecht.

Farrell, M. 1957). The measurement of productive efficiency. Journal of the Royal Statistical Society. Series A ,120(3), 253-290.

Hwang, S. N. and Chang, T. Y. (2003). Using data envelopment analysis to measure hotel managerial efficiency change in taiwan. Tourism Management, 24(4), 357-369.

İstanbul İl Kültür ve Turizm Müdürlüğü, turizm istatistikleri raporu (2021, 12 Haziran). Erişim adresi https://istanbul.ktb.gov.tr/Eklenti/82487, subat2021-turizm-istatistikleri-duzeltmepdf.pdf?0

Jafari, Y., (2014). Malmquist productivity index for multi time periods. International Journal of Data Envelopment Analysis, 2, 315-322.

Jingrong S., Jie Z., Jinhe Z., Jinhai, M. and Yuling, Z. (2015). Total factor productivity assessment of tourism industry: evidence from china, Asia Pacific Journal of Tourism Research, 20:3, 280294.

Johns, N., Howcroft, B. and Drake, L. (1997). The use of data envelopment analysis to monitor hotel productivity. Progress in Tourism and Hospitality Research, 3, 119-127.

Kecek, G., (2010). Veri zarflama analizi: teori ve uygulama örneği, Ankara: Siyasal Kitabevi. 
Keskin Benli, Y., (2006). İstanbul menkul kıymetler borsası imalat sanayi için etkinlik ve toplam faktör verimliliği analizi, Ankara: Seçkin Yayıncilık.

Keskin Benli, Y., (2012). Veri zarflama analizi (VZA) ve malmquist toplam faktör verimliliği (TFV): konaklama işletmelerinde bir uygulama. Ege Akademik Bakış, 12, 3, 369-382.

Köksal, C. D. and Aksu, A. A., (2007). Efficiency evaluation of a group travel agencies with data envelopment analysis (DEA): A case study in the antalya region, Turkey. Tourism Management, 28(3), $830-834$. https://doi.org/10.1016/j.tourman.2006.05.013G et rights and content

Kosmaczewska, J., (2014). Tourism interest and the efficiency of its utilisation based on the example of the eu countries. Acta Scientiarum Polonorum Oeconomia, 13(1), 77-90.

Kök, R. ve Deliklitaş, E., (2003). Endüstri iktisadında verimlilik ölçme ve strateji geliştirme teknolojileri. İzmir: Dokuz Eylül Üniversitesi İktisati İdari Bilimler Fakültesi Yayını,40(3), 6871.

Kültür ve Turizm Bakanlığı. Tesis istatistikleri (2019, 10 Haziran). Erişim adresi https://yigm.ktb.gov.tr/TR-

201131/tesisistatistikleri.html.

Lee, Y., Lu, L.T. and Sung, A.D. (2012). A measure to the operational performance of international hotels in taiwan: dea and malmquist approach. Review of Economics and Finance, 2, 73-83.

Liu, F. and Wang, P. (2008). DEA malmquist productivity measure: taiwanese semiconductor companies. International Journal of production Economics, 112, 65-72.

Luo, H., Yang, Y. and Law, R. (2014). How to achieve a high efficiency level of the hotel industry. International Journal of Contemporary Hospitality Management, Vol. 28, 1140-1161.

Mahadevan, R. (2002). A dea approach to understanding the productivity growth of malaysia's manufacturing industries. Asia Pasific Journal of Management, Volume 19, Issue 4, pp. 587-600.

Malmquist, S., (1953). Index numbers and indifference surfaces. Trabajos de Estadistica, 4, 209-242.

Özsağır, A. ve Akın, A., (2012). Hizmetler sektörü içinde hizmet ticaretinin yeri ve karşılaştırmalı bir analizi. Elektronik Sosyal Bilimler Dergisi, 11(41), 311-331.

Reynolds, D. and Biel, D., (2007). Incorporating satisfaction measures into a restaurant productivity index. International Journal of Hospitality Management, 26, 352-361.

Shang, JK., Hung, W.K., Fang, Lo C. and Wang, F., (2008). Ecommerce and hotel performance: three-stage dea analysis, The Service Industries Journal, 28:4, 529-540.

Türkiye İstatistik Kurumu. (2019, 12 Mayıs). Erişim adresi

https://biruni.tuik.gov.tr/bolgeselistatistik/degisk enlerUzerindenSorgula.do?durum=acKapa\&me nuNo=273\&altMenuGoster $=1 \&$ secilenDegisken Listesi $=$

Türkiye İstatistik Kurumu. (2020, 15 Mart). Erişim adresi

https://biruni.tuik.gov.tr/bolgeselistatistik/degisk enlerUzerindenSorgula.do?durum=acKapa\&me nuNo=113\&altMenuGoster $=1 \&$ secilenDegisken Listesi $=$

Türkiye İstatistik Kurumu. (2021, 16 Haziran). Erişim adresi

https://biruni.tuik.gov.tr/bolgeselistatistik/tablo YilSutunGetir.do?durum=yillariGetir\&menuNo $=518 \&$ altMenuGoster $=0 \&$ tabloNo $=337 \#$

Tsai, H.; Wu, J. and Zhou, Z., (2011). Managing efficiency in international tourist hotels in taipei using a dea model with non-discretionary inputs. Asia Pacific Journal of Tourism Research, 16, 417-432.

UNWTO-International tourism highlight; world tourism organization. (2019, April 21). Erişim adresi https://www.eunwto.org/doi/pdf/10.18111/9789284421152, Madrid, Spain, pp. 1-24

Vergil, H. ve Abasız, T. (2008). Toplam faktör verimliliği hesaplanması ve büyüme ilişkisi: collins bosworth varyans ayrıştırması. Kocaeli Üniversitesi Sosyal Bilimler Dergisi, (16), 160188.

Yi, T. and Liang, M. (2015). Evolutional model of tourism efficiency based on the dea method: A case study of cities in guangdong province, China. Asia Pacific Journal of Tourism Research, 20, 789-806. https://doi.org/10.1080/10941665.2014.932294. 